\title{
Emerging Role of Hepatobiliary Magnetic Resonance Contrast Media and Contrast-Enhanced Ultrasound for Noninvasive Diagnosis of Hepatocellular Carcinoma: Emphasis on Recent Updates in Major Guidelines
}

\author{
Tae-Hyung Kim, $M D^{1}$, Jeong Hee Yoon, $M D^{1,2}$, Jeong Min Lee, $M D^{1,2,3}$ \\ ${ }^{1}$ Department of Radiology, Seoul National University College of Medicine, Seoul, Korea; ${ }^{2}$ Department of Radiology, Seoul National University \\ Hospital, Seoul, Korea; ${ }^{3}$ Institute of Radiation Medicine, Seoul National University Medical Research Center, Seoul, Korea
}

Hepatocellular carcinoma (HCC) can be noninvasively diagnosed on the basis of its characteristic imaging findings of arterial phase enhancement and portal/delayed "washout" on computed tomography (CT) and magnetic resonance imaging (MRI) in cirrhotic patients. However, different specific diagnostic criteria have been proposed by several countries and major academic societies. In 2018, major guideline updates were proposed by the Association for the Study of Liver Diseases, European Association for the Study of the Liver (EASL), Korean Liver Cancer Association and National Cancer Center (KLCA-NCC) of Korea. In addition to dynamic CT and MRI using extracellular contrast media, these new guidelines now include magnetic resonance imaging (MRI) using hepatobiliary contrast media as the first-line diagnostic test, while the KLCA-NCC and EASL guidelines also include contrast-enhanced ultrasound (CEUS) as the second-line diagnostic test. Therefore, hepatobiliary MR contrast media and CEUS will be increasingly used for the noninvasive diagnosis and staging of HCC. In this review, we discuss the emerging role of hepatobiliary phase MRI and CEUS for the diagnosis of HCC and also review the changes in the HCC diagnostic criteria in major guidelines, including the KLCA-NCC practice guidelines version 2018. In addition, we aimed to pay particular attention to some remaining issues in the noninvasive diagnosis of HCC.

Keywords: Hepatocellular carcinoma; Diagnosis; Criteria; Practice guidelines; Imaging techniques

\section{INTRODUCTION}

Hepatocellular carcinoma (HCC) is the sixth most common cancer and the second leading cause of cancerrelated death worldwide (1). Prior to the application of organized screening and surveillance of high-risk patients for HCC, the mortality attributed to HCC was roughly comparable to its incidence (2). Since the introduction of

Received July 14, 2018; accepted after revision February 3, 2019. Corresponding author: Jeong Min Lee, MD, Department of Radiology, Seoul National University College of Medicine, 103 Daehak-ro, Jongno-gu, Seoul 03080, Korea.

- Tel: (822) 2072-2254 - Fax: (822) 743-6385

- E-mail: jmlshy2000@gmail.com

This is an Open Access article distributed under the terms of the Creative Commons Attribution Non-Commercial License (https://creativecommons.org/licenses/by-nc/4.0) which permits unrestricted non-commercial use, distribution, and reproduction in any medium, provided the original work is properly cited. systematic screening and surveillance for HCC in the mid1990s, however, 5-year survival has markedly improved (3). Previous studies have since demonstrated that early detection of HCC definitely improved the prognosis of patients with $\mathrm{HCC}(4-6)$ and that screening/surveillance tests utilizing imaging examinations were better than any other screening/surveillance tests, including blood tests, for early diagnosis of HCC (7). Furthermore, the critical role that imaging has played in the screening, surveillance, diagnosis, staging, management, and monitoring of treatment response has further contributed to improvement in HCC mortality (8-10). Unlike most other malignancies, $\mathrm{HCC}$ can be diagnosed noninvasively, and treatment may be initiated based on imaging alone, without confirmatory biopsy (11-13). For this reason, in most current clinical practice guidelines, contrast-enhanced (CE) computed tomography (CT) and magnetic resonance imaging (MRI) 
have supplanted biopsy as the preferred method of diagnosing $\mathrm{HCC}$ with characteristic imaging features (8). This noninvasive diagnosis of HCC based on imaging tests alone is mainly possible due to the following reasons: 1 ) the pretest probability of HCC has been demonstrated to be sufficiently high in cirrhotic patients, and 2) the high specificity and positive predictive value of HCC imaging criteria in the selected screening cohort (11). The typical imaging hallmark of HCC is a combination of arterial phase hyperenhancement (APHE) and washout on the portal venous and/or delayed phases, which reflects the vascular derangement that occurs during hepatocarcinogenesis (14).

Over the past two decades, many major organizations have proposed HCC imaging systems, including the Association for the Study of Liver Disease (AASLD) $(11,15)$, European Association for the Study of the Liver (EASL) (16), AsianPacific Association for the Study of the Liver (APASL) (17), Liver Imaging Reporting and Data System (LI-RADS) (18, 19), the Organ Procurement and Transplantation Network system (20), Japan Society of Hepatology (JSH) (21), and the Korean Liver Cancer Study Group and the National Cancer Center (KLCSG-NCC) (22). The designs of these HCC imaging systems have varied across geographic areas so as to address different target populations, resources, and treatment practices (10). Despite these regional variations, imaging-based HCC guidelines have continued to improve the consistency and standardization of the acquisition, interpretation, and reporting of liver examinations $(10,23)$. These guidelines have also been continually updated to reflect the most recent radiological and technological advances, as well as our constantly improving understanding of HCC pathophysiology. In 2018, AASLD $(11,15)$ and EASL $(16)$ published updated versions of their guidelines. LI-RADS, which is endorsed by the American College of Radiology (ACR), has been updated 2 years in a row, in 2017 (18) and 2018 (19). The Korean Liver Cancer Association (KLCA)-NCC (previously KLCSG-NCC) has also release new 2018 version of the KLCA-NCC guideline and it is expected to be published soon (in press) (24). The key change this year in both AASLD and EASL guidelines is the addition of hepatobiliary contrast media (HBCM)-enhanced MRI as the first-line diagnostic test to dynamic CT and MRI using extracellular contrast media (ECCM), while the KLCA-NCC and EASL guidelines also include CE ultrasound (CEUS) as the second-line diagnostic test. Therefore, it can be expected that HBCM-enhanced MRI and CEUS will play increasingly important roles in the noninvasive diagnosis of
HCC in the years to come.

In this review, we will address the emerging role of HBCM-enhanced MRI and CEUS in the diagnosis of HCC and discuss several unsolved issues when using these two diagnostic tests. In addition, we will briefly review the new HCC diagnostic criteria endorsed by the KLCA-NCC practice guidelines version 2018 and compare them with the other aforementioned guidelines. Finally, we would like to address some remaining issues in the noninvasive diagnosis of HCC.

\section{Role of HBCM}

HBCM consists of two gadolinium-based contrast agents (GBCA)-gadoxetate disodium (gadoxetic acid or gadolinium ethoxybenzyl diethylenetriamine pentaacetic acid [Gd-EOB-DTPA]) and gadobenate dimegluminethat show the dual properties of "conventional" GBCAs and hepatobiliary contrast agents. As these agents show hepatocellular uptake and biliary excretion, they enable the visualization of a key feature of hepatocarcinogenesis in vivo, which is the alteration of transporters on the cellular membranes of hepatocytes (14). Expression of the organic anion transporting polypeptide (OATP) 1B1/3 assessed by $\mathrm{HBCM}$ reduces with tumor progression $(14,25)$. As a result, a persistent and strong enhancement of the normal background liver via cellular uptake can be observed during the hepatobiliary phase (HBP), whereas premalignant or malignant hepatocellular tumors would have diminished or absent transporter function and therefore show hypoenhancement on the HBP, which appears earlier than the hemodynamic changes in hepatocarcinogenesis (26, 27). Furthermore, the improved lesion-to-liver contrast during the HBP leads to higher sensitivity for the detection of HCCs than with CT or MRI using ECCM (28). Considering the results of previous studies in which the early detection of HCCs followed by prompt treatment could significantly improve outcome (4-6), the higher sensitivity of HBCM would have great clinical value, potentially leading to improved survival (29). According to a recent retrospective cohort study, additional evaluation using Gd-EOB-DTPA MRI along with dynamic $\mathrm{CT}$ in patients with a single nodular $\mathrm{HCC}$ led to the detection of additional HCC nodules in $16.4 \%$ of patients, reduced recurrence in $28 \%$, and decreased overall mortality in $35 \%$ (29). Therefore, recognizing the benefit of HBCM-enhanced MRI, both APASL v. 2017 and KLCSG-NCC v. 2014 guidelines include HBCM-enhanced MRI as the firstline diagnostic test $(17,22)$. 
However, controversies remain regarding the ideal timing to determine "washout" on Gd-EOB-DTPA-enhanced MRI. Indeed, extending the phases of washout to the transient phase or including the hypointensity on the HBP in the diagnosis of HCC may increase sensitivity but inevitably lower specificity at the same time $(30,31)$. Using the washout in the portal or delayed phase of ECCM on MRI in contemporary guidelines, the overall sensitivity and specificity for noninvasive diagnosis of $\mathrm{HCC}$ according to several prospective studies have been reported to be $65-89 \%$ and $91-100 \%$, respectively $(32,33)$. If Gd-EOBDTPA MRI is used, the criteria using washout in the portal phase would show very high specificity but have low sensitivity, particularly for nodules $<2 \mathrm{~cm}$ in diameter (74.5\%) (31). Thus, the criteria to determine "washout" on HBCM-enhanced MRI may depend on the diagnostic aim desired by radiologists and clinicians, whether it is high sensitivity or high specificity (34). In most Western countries, where the prevalence of HCC is not very high, a conservative approach may seem reasonable as overdiagnosis of HCCs may lead to an unnecessary increase in the priority for liver transplantation allocations. On the other hand, in Asian countries where the prevalence of HCC is quite high, diagnostic criteria providing higher sensitivity with reasonably high specificity may be more appropriate because early detection of HCCs may provide a chance for earlier application of potentially curative treatments such as radiofrequency ablation or surgical resection. In addition, as liver transplantations are frequently used as a salvage operation after several attempts, including interventional procedures or surgical resections, in Asian countries, a mild reduction in the specificity for HCC diagnosis may be acceptable if high sensitivity is achievable within certain diagnostic criteria. Considering the widespread use of GdEOB-DTPA MRI and clinicians' preference for the early diagnosis and treatment of HCCs in Korea (35), the KLCANCC Guidelines version 2018 adopt washout on the portal or transitional phase and hypointensity on HBP. Nevertheless, in order to preserve specificity, the 2018 KLCA-NCC guidelines also apply the exclusion criteria of a targetoid appearance or marked T2 hyperintensity to rule out the most common confounders that show the washout appearance on HBP, i.e., hemangiomas, cholangiocarcinomas (CCs), and combined hepatocellular-CCs (30). Therefore, the revised Korea guidelines can be expected to increase sensitivity while preserving specificity for the diagnosis of HCCs.

Another important merit of HBP is that hypointense nodules on HBP without APHE have a higher risk of progressing to typical hypervascular HCCs than iso- or hyperintense nodules $(36,37)$, and thus the signal intensity of HCCS on HBP has been reported to be a prognostic factor (38). Although most HCCs show hypointensity on HBP, the variable hyperintense signal characteristics of some HCCs $(-10 \%)$ with increased expression rates of OATP transporters in HBP should be considered, especially when they are accompanied by a focal defect within the contrast uptake and a hypointense rim (39).

One major drawback of Gd-EOB-DTPA MRI in comparison with ECCM-enhanced dynamic MRI, however, is the suboptimal or non-diagnostic arterial phase images owing to transient dyspnea or the lower gadolinium concentration of gadoxetic acid compared to other ECCMs (40). Fortunately, however, a previous study has demonstrated that multiple arterial phase imaging with rapid imaging sequences or a modified injection protocol can minimize this problem (41).

\section{Role of CEUS}

CEUS is a valuable technique for the characterization of focal liver lesions and is based on the evaluation of hemodynamic alterations (42). The sensitivity for depiction of arterial hypervascularity on CEUS can potentially reduce the number of invasive biopsies otherwise required for such indeterminate nodules in the cirrhotic liver (43). Two major contributing factors of this advantage are the real-time imaging capability of ultrasound and the inherent superior sensitivity of CEUS to microbubbles in comparison with the sensitivity of CT or MRI to iodinated or GBCA (44). Two types of contrast agents are used for CEUS: intravascular contrast agents (also known as pure blood-pool contrast agents) and postvascular phase agents taken up by Kupffer and/or reticuloendothelial cells. Sulfur hexafluoride with a phospholipid shell (SonoVue: Bracco S.p.A., Milan, Italy) and octafluoropropane (perflutren) with a lipid shell (Definity/ Luminity: Lantheus Medical, Billerica, MA, USA) are common intravascular agents while Sonazoid (GE Healthcare, Chalfont St. Giles, UK) is a postvascular phase agent. Unlike SonoVue or Definity, Sonazoid provides additional Kupffer phase images (usually 10-60 minutes after its injection) in which typical HCCs show low echogenicity, indicating a lack of contrast uptake due to the absence of Kupffer cells and/or reticuloendothelial cells (45).

There are several distinctive features of CEUS in comparison to CT/MRI that reflect the dissimilarities in 
their underlying methods of image acquisition and types of contrast agent used. First, CEUS allows real-time evaluation of the enhancement of a nodule, resulting in more sensitive detection of APHE than CT or MRI which may fail to demonstrate transient APHE in the early arterial phase (4648). Therefore, CEUS can be considered to be an alternative imaging option for nodules categorized in CT or MRI as LR-3 or LR-4 due to the absence of APHE, because some of these nodules potentially could be upgraded to LR-5 if APHE is shown on CEUS (44). Second, there are no vascular pseudolesions on CEUS. Arterioportal shunts are the most common vascular pseudolesions in cirrhotic livers on CT and MRI $(46,49,50)$. Although most arterioportal shunts are promptly defined due to their typical wedge shape and location on CT or MRI, some may be mistaken for true lesions and may obscure true HCCs, lowering the sensitivity for HCC detection. On the other hand, since CEUS rarely depicts any arterioportal shunt, APHE on CEUS is highly likely to indicate HCCs in high-risk patients, even in the absence of washout (51).

The usage of CEUS for the diagnosis of HCCs has been variably endorsed by international and national scientific societies $(52,53)$. The Japanese, Canadian, Italian, and Asia Pacific hepatology or liver cancer societies were the first to endorse the use of CEUS to establish a diagnosis of HCC, (17, $21,54,55)$, most commonly as a second-line technique when CT or MRI proved inconclusive or when they are contraindicated. Recently, the EASL guideline also adopted CEUS with intravascular contrast agents as a secondary diagnostic test (16), whereas the AASLD guideline (15) has not yet accepted CEUS for the diagnosis of HCC. As of now, most guidelines except LI-RADS recommend CEUS as a secondary imaging modality, most likely due to its several potential weaknesses, i.e., the lower detection rate for washout of HCCs than with CT or MRI $(51,56,57)$, limited capability of staging $(51,56)$, poor performance in some patients with a poor sonic window or advanced cirrhosis, and lack of availability except in expert centers (15). In addition, most guidelines that have adopted CEUS as a diagnostic tool accept the use of intravascular contrast agents, whereas JSH and APASL guidelines $(17,21)$ only accept the use of Sonazoid.

It has previously been questioned whether CEUS can be utilized to derive a specific diagnosis of $\mathrm{HCC}$ due to the potential risk of a misdiagnosis in cases of $\mathrm{CC}$, which occurs at a rate of $2-5 \%$ among all new nodules in liver cirrhosis $(58,59)$. Furthermore, approximately $50 \%$ of all mass-forming CCs in cirrhosis show global APHE followed by washout in CEUS, leading to misdiagnosis as HCC (60, 61). These similarities in the enhancement features of HCC and CC on CEUS, which are different from those on CT or MRI, can be attributed to the different pharmacokinetic features of contrast agents in CEUS from ECCMs used for CT or MRI. Contrast agents for CT or MRI tend to diffuse through the vascular endothelium and accumulate in the interstitial tissue, whereas most contrast agents for CEUS, except Sonazoid, are purely intravascular microbubbles (44). However, subsequent studies (62-64) have demonstrated that CEUS can show different APHE characteristics and timing and degree of washout between HCCs and CCs. Specifically, many HCCs showed APHE followed by late (> 60 seconds) and mild washout $(65,66)$ (Fig. 1) on CEUS, whereas many CCs showed APHE followed by early $(<60$ seconds) and marked washout $(62,63)$ (Fig. 2). These refined criteria for HCC on CEUS preserve its extremely high positive predictive value for the diagnosis of HCC while improving its capacity to differentiate other malignant lesions such as CC (58). Indeed, a recent large retrospective study (58) including more than 1000 lesions in cirrhosis proved that these new criteria for HCC on CEUS had a positive predictive value of almost $99 \%$ for HCCs and a positive likelihood ratio of 15.5 , with no false-positive diagnoses owing to CCs. In another recent prospective multicenter study (67) involving 10-20 mm nodules, CEUS showed a higher specificity of $92.9 \%$ compared to CT (76.8\%) and MRI (83.2\%). Furthermore, after the first inconclusive diagnosis with CT or MRI, CEUS as the second imaging technique showed the highest specificity with only a slight drop in sensitivity for nodules of $10-20 \mathrm{~mm}$ and the highest sensitivity and specificity for nodules of $20-30 \mathrm{~mm}$. On the basis of these recent promising results obtained with these refined CEUS criteria for HCC, these criteria have now been adopted in Italy (Italian Association for the Study of the Liver) (54), the ACR in the USA (68), as well as in the updated guidelines in 2018 endorsed by EASL and KLCA-NCC $(16,24)$. However, it is critical for clinicians to know that these stringent criteria for HCC on CEUS may provide such high specificity for HCC, unavoidably lowering sensitivity.

The ACR recently updated their CEUS LI-RADS version 2017 similar to LI-RADS for CT and MRI (68). CEUS LI-RADS provides a diagnostic algorithm that categorizes nodules from LR-1 (definitely benign) to LR-5 (definitely HCC), reflecting the readers' certainty in the diagnosis of $\mathrm{HCC}$, according to the lesion size and enhancement patterns. 

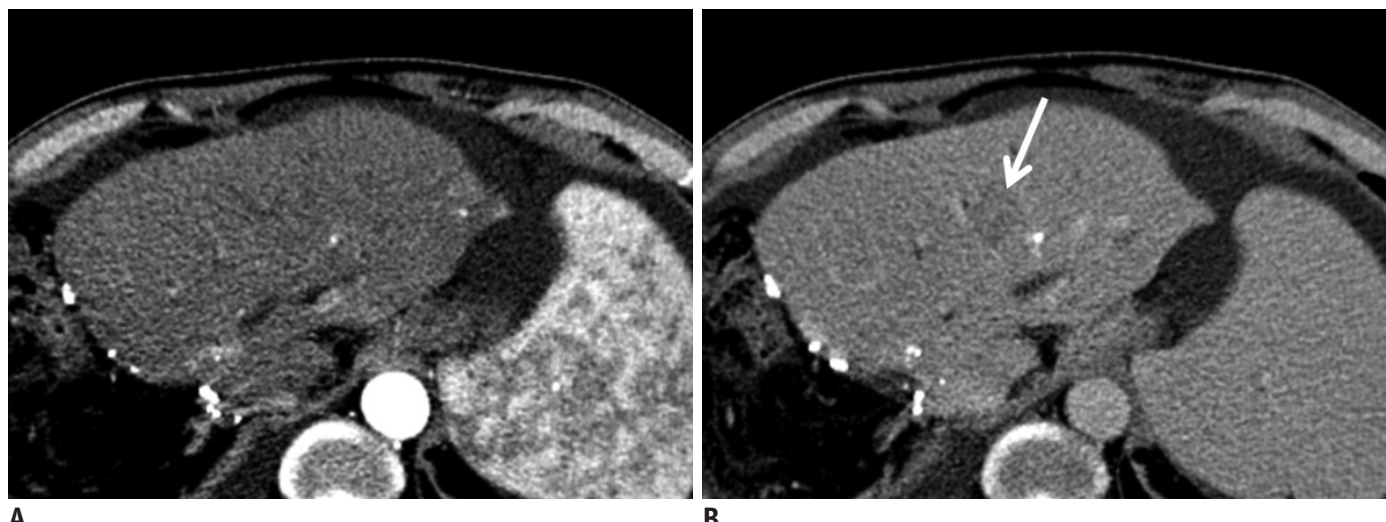

A

B
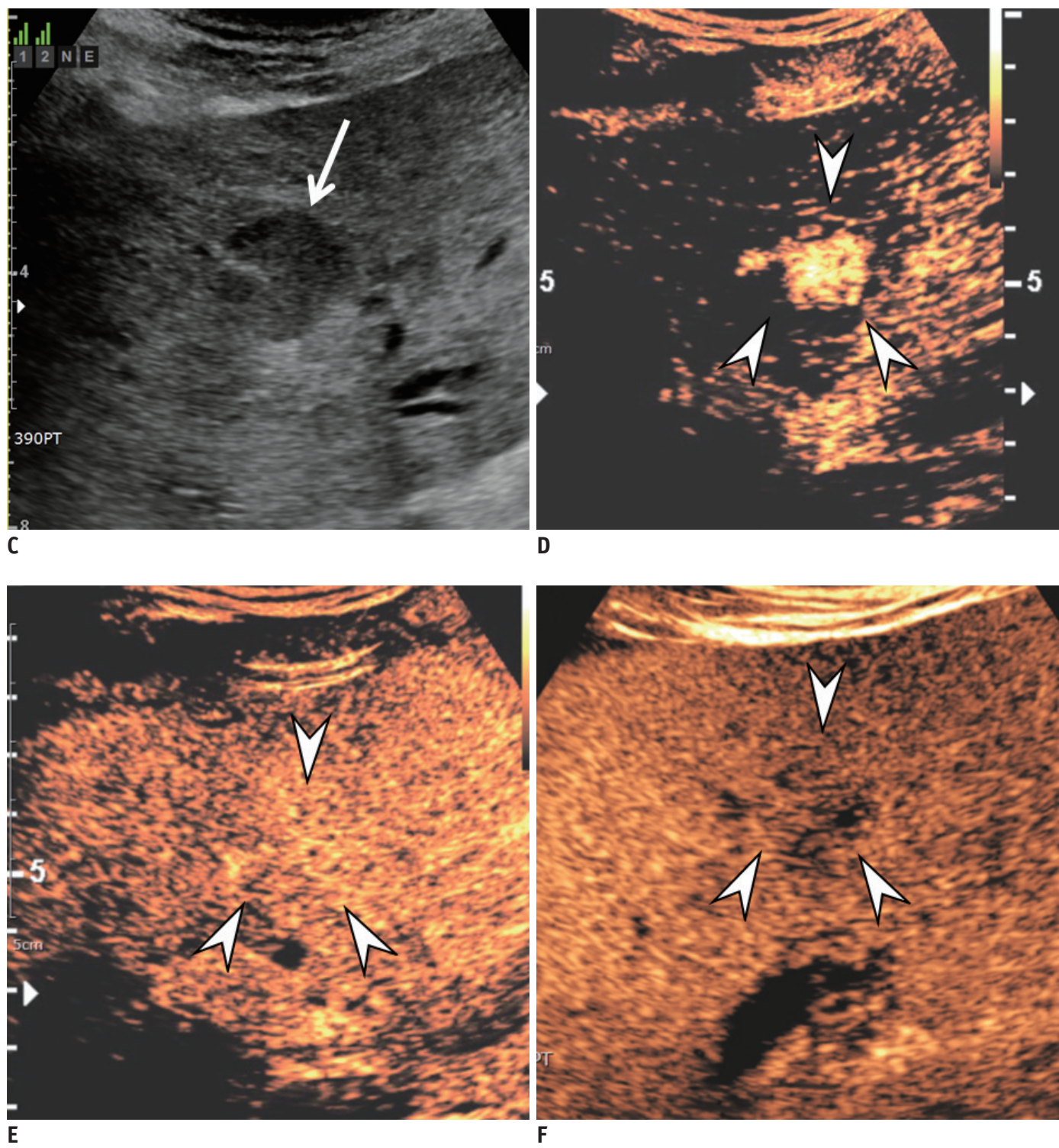

Fig. 1. Typical CEUS features of HCC in 60-year-old man with history of right hemihepatectomy for HCC.

On arterial (A) and delayed (B) phases of CT, 2.3-cm subtle low-attenuated nodule (arrow) is visible only in delayed phase at left lateral segment of liver. Nodule (arrow) shows low echogenicity on gray-scale US (C). On CEUS, nodule (arrowheads) shows hyperenhancement in arterial phase (25 seconds after contrast injection) (D), isoechogenicity in portal phase (45 seconds) (E), and mild washout occurring only in late phase (200 seconds) (F), compatible with LI-RADS 5. CEUS = contrast-enhanced ultrasound, CT = computed tomography, HCC = hepatocellular carcinoma, LIRADS = Liver Imaging Reporting and Data System, US = ultrasound 

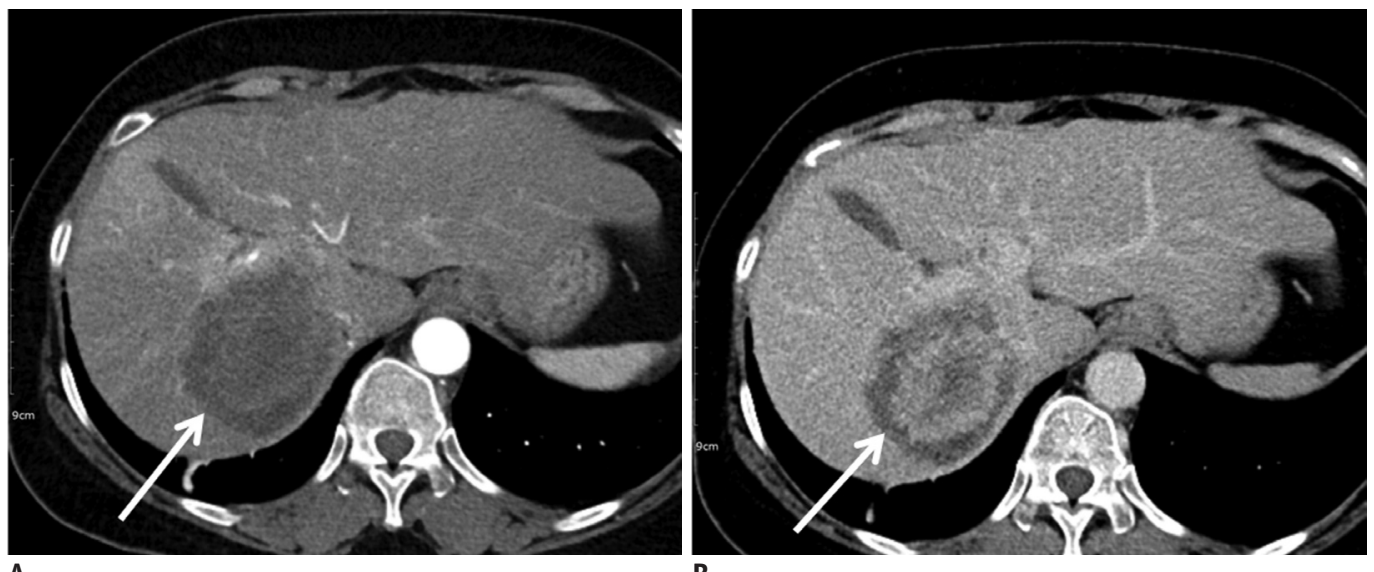

A

B
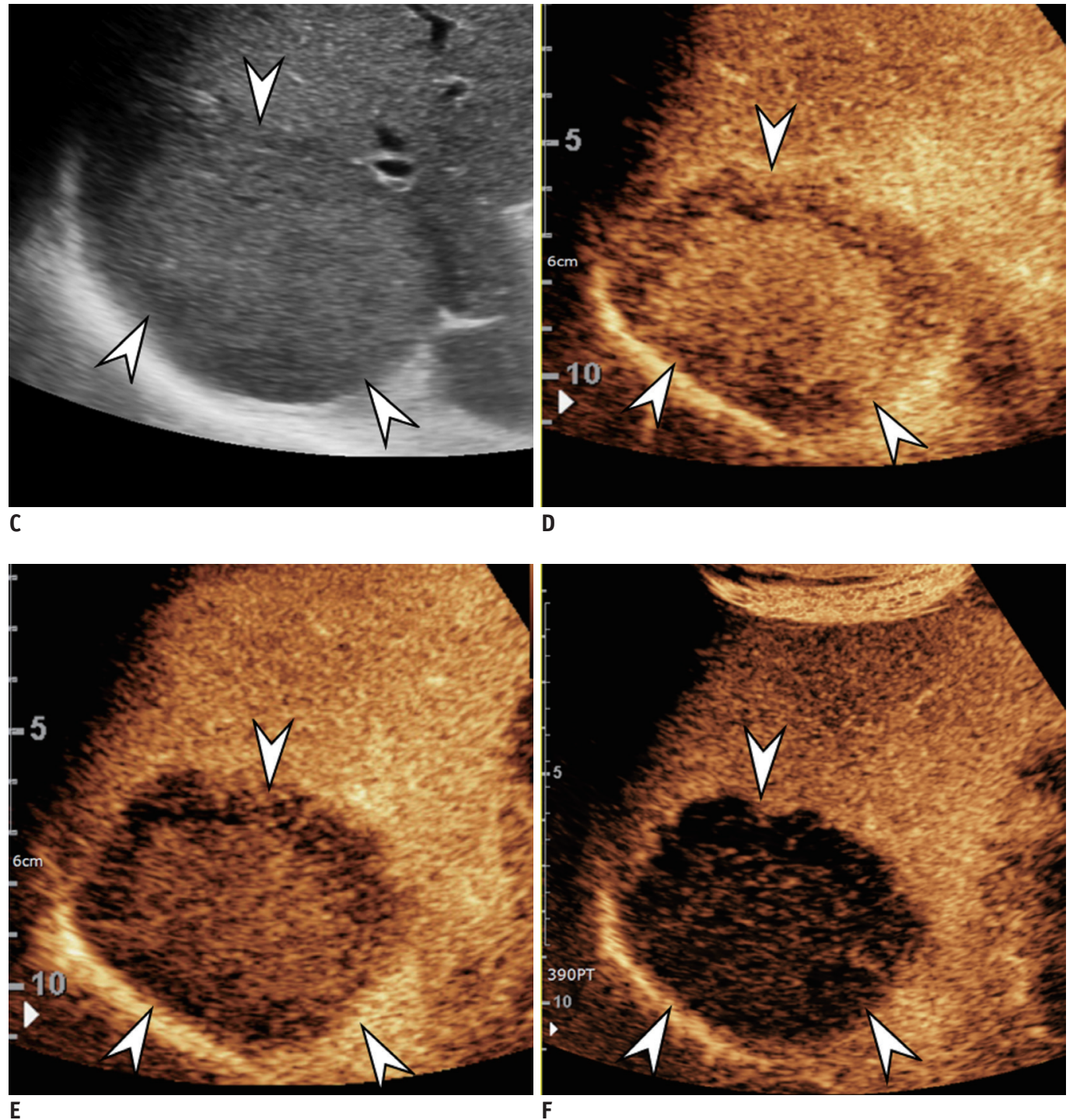

Fig. 2. Typical CEUS findings of cholangiocarcinoma in 57 -year-old woman with $\mathrm{CHB}$ viral infection.

On arterial (A) and portal (B) phases of CT, 8-cm low-attenuated mass (arrows) is seen with equivocal hyperenhancement in arterial phase and central hyperenhancement with peripheral low attenuation in 3-minute delayed phase at right lobe of liver. Mass (arrowheads) shows isoechogenicity on gray-scale US (C). On CEUS, mass (arrowheads) shows heterogeneous central hyperenhancement in arterial phase (20 seconds after contrast injection) (D), marked washout in both portal (60 seconds) (E) and late (180 seconds) (F) phases, compatible with LI-RADS-M. Lesion was confirmed as cholangiocarcinoma via biopsy. $\mathrm{CHB}=$ chronic hepatitis $\mathrm{B}$ 


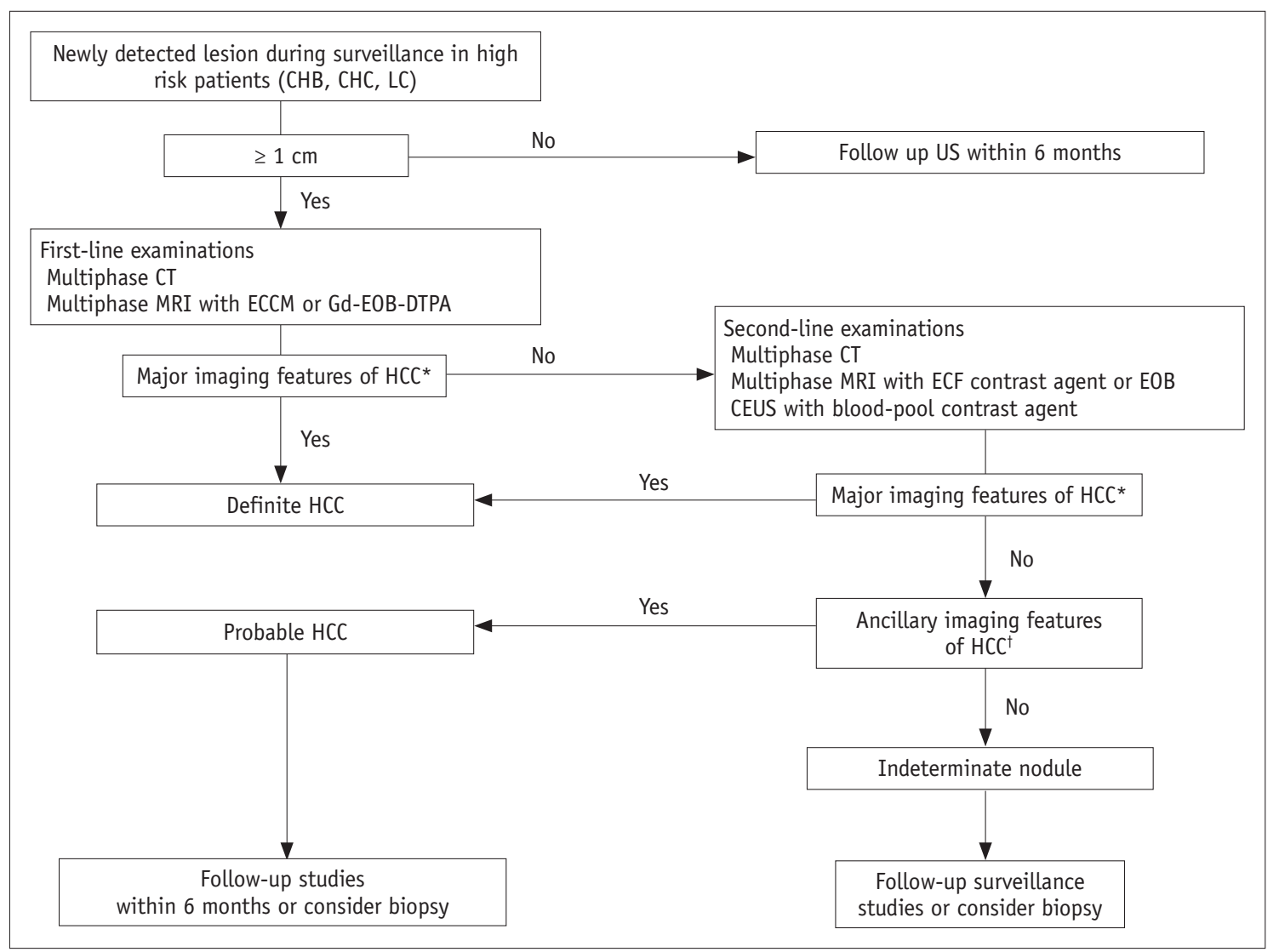

Fig. 3. Diagnostic algorithm for suspected HCC using new KLCA-NCC practice guidelines. *Major imaging features of HCC include arterial hyperenhancement and washout appearance during portal venous, delayed, or HBP on multiphasic CT or MRI using extracellular contrast agents or EOB in nodules $\geq 1 \mathrm{~cm}$ in diameter. However, lesion should not show either marked T2 high SI or targetoid appearance on DWI or contrast-enhanced sequences. On CEUS as second-line examinations, major imaging features include arterial hyperenhancement and late ( $\geq 60$ seconds) and mild washout, 'In nodule(s) with some but not all aforementioned major imaging features of HCC, category of "probable" HCC can be assigned only when lesion fulfills at least one item from each of following two categories of ancillary imaging features. Two categories which make up ancillary imaging features are findings favoring malignancy in general (mild-to-moderate T2 hyperintensity, restricted diffusion, HBP hypointensity, interval growth) and those favoring HCC in particular (non-enhancing capsule, mosaic architecture, nodule-in-nodule appearance, fat or blood products in mass). These criteria should be applied only to lesion which shows neither marked T2 hyperintensity nor targetoid appearance on DWI or contrast-enhanced sequences. DWI = diffusion-weighted imaging, ECCM = extracellular contrast media, Gd-EOB-DTPA = gadolinium ethoxybenzyl diethylenetriamine pentaacetic acid, HBP = hepatobiliary phase, KLCA-NCC = Korean Liver Cancer Association-National Cancer Center, $\mathrm{LC}=$ liver cirrhosis, $\mathrm{MRI}=$ magnetic resonance imaging, $\mathrm{SI}=$ signal intensity

LR-5 nodules can be categorized by the presence of cirrhotic nodules showing APHE followed by late ( $>60$ seconds) and mild washout, and can be treated as HCCs without biopsy or further imaging. Because LR-5 criteria are very stringent to achieve a high specificity for HCCs, HCCs may occur in other categories, most commonly in categories LR-3 and LR-4 for well-differentiated HCC and in LR-M for poorly differentiated $\mathrm{HCC}$, for which final diagnoses are usually achieved with histology.

\section{New Changes in the KLCA-NCC Practice Guidelines Version 2018}

The diagnostic algorithm of the KLCA-NCC practice guidelines is provided in Figure 3. The 2018 KLCA-NCC practice guidelines provide several statements regarding the diagnosis of HCC (Table 1). The major changes in the KLCANCC 2018 guidelines compared to the previous version can be summarized as follows:

First, the guidelines have adopted new non-binary decisions, e.g., definite, probable, and indeterminate nodules. Second, the guidelines now allow multi-parametric assessment of CT and MRI and therefore, several ancillary features can be used to make a "probable HCC diagnosis." Third, the guidelines now include "washout" not only in the portal or transitional phase, but also hypointensity on the HBP after applying the exclusion criteria of a targetoid appearance or marked T2 hyperintensity on gadoxetic 
Table 1. Summary of KLCA-NCC Practice Guidelines Version 2018 for Diagnosis of HCC

\begin{tabular}{|c|c|}
\hline Topic & Recommendations \\
\hline agnosis of $\mathrm{HCC}$ & $\begin{array}{l}\text { 1) Diagnosis of } \mathrm{HCC} \text { can be made with either pathology or noninvasive imaging in high-risk groups (CHB, } \mathrm{CHC} \text {, or } \\
\text { cirrhosis) }\end{array}$ \\
\hline $\begin{array}{l}\text { Diagnostic } \\
\text { imaging } \\
\text { modalities }\end{array}$ & $\begin{array}{l}\text { 2) In at-risk patients with lesion } \geq 1 \mathrm{~cm} \text { in size on surveillance tests, multiphase CT or multiphase MRI with } \\
\text { extracellular contrast agents or hepatobiliary contrast agents should be performed as first-line exam. If first-line } \\
\text { imaging is inconclusive, second-line imaging examinations can be applied. Second-line imaging exams include } \\
\text { multiphase CT, multiphase MRI with extracellular contrast agents or hepatobiliary contrast agents, and CEUS with } \\
\text { blood pool contrast agents }\end{array}$ \\
\hline efinite $\mathrm{HCC}$ & $\begin{array}{l}\text { 3) Imaging diagnosis can be applied to nodule } \geq 1 \mathrm{~cm} \text { detected in at-risk patients during surveillance on basis of } \\
\text { following radiologic hallmarks: } \\
\text { (a) On multiphase CT or MRI with extracellular contrast agents, major imaging features for "definite" diagnosis of } \\
\text { HCC are defined as APHE with washout in portal venous or delayed phases. } \\
\text { (b) On multiphase MRI with hepatobiliary contrast agents, major imaging features for "definite" diagnosis of HCC } \\
\text { are defined as APHE with washout in portal venous, delayed, or HBPs. These criteria should be applied only to } \\
\text { lesion which does not show either marked T2 hyperintensity or targetoid appearance on DWI or CE sequences }\end{array}$ \\
\hline robable HCC & $\begin{array}{l}\text { 4) In nodule(s) with some but not all of aforementioned major imaging features of HCC, category of "probable" HCC } \\
\text { can be assigned only when lesion fulfills at least one item from each of following two categories of ancillary } \\
\text { imaging features. Two categories which make up ancillary imaging features are findings favoring malignancy in } \\
\text { general (mild-to-moderate T2 hyperintensity, restricted diffusion, HBP hypointensity, interval growth) and those } \\
\text { favoring HCC in particular (no-enhancing capsule, mosaic architecture, nodule-in-nodule appearance, fat or blood } \\
\text { products in mass). These criteria should be applied only to lesion which shows neither marked T2 hyperintensity } \\
\text { nor targetoid appearance on DWI or CE sequences }\end{array}$ \\
\hline Follow-up & $\begin{array}{l}\text { 5) For "probable" HCC, follow-up imaging studies in less than } 6 \text { months or biopsy need to be considered to establish } \\
\text { diagnosis. For indeterminate lesions, any changes in imaging patterns or serum tumor markers should be closely } \\
\text { monitored, or biopsy can be considered for pathologic diagnosis } \\
\text { 6) In patients with subcentimeter-sized nodules, follow-up with interval of less than } 6 \text { months is recommended while } \\
\text { closely monitoring interval growths or changes in imaging patterns }\end{array}$ \\
\hline Recurred HCC & $\begin{array}{l}\text { 7) New or growing nodule which does not show typical imaging hallmarks of HCC found in follow-up of patient } \\
\text { diagnosed with HCC could be diagnosed as HCC based on ancillary imaging features }\end{array}$ \\
\hline $\begin{array}{l}\text { Risk of radiation } \\
\text { related to use } \\
\text { of } \mathrm{CT}\end{array}$ & $\begin{array}{l}\text { 8) Although strict limitation of radiation dose from CT for diagnosis and follow-up evaluation of HCC is not } \\
\text { recommended, unnecessary radiation exposure from CT should be avoided. Techniques with reduced radiation dose } \\
\text { and alternative imaging studies should be considered }\end{array}$ \\
\hline
\end{tabular}

APHE $=$ arterial phase hyperenhancement, $\mathrm{CE}=$ contrast-enhanced, $\mathrm{CEUS}=$ contrast-enhanced ultrasound, $\mathrm{CHB}=$ chronic hepatitis $\mathrm{B}, \mathrm{CHC}$ $=$ chronic hepatitis $\mathrm{C}, \mathrm{CT}=$ computed tomography, DWI = diffusion-weighted imaging, $\mathrm{HBP}=$ hepatobiliary phase, $\mathrm{HCC}=$ hepatocellular carcinoma, KLCA-NCC = Korean Liver Cancer Association-National Cancer Center, MRI = magnetic resonance imaging, US = ultrasound

acid-enhanced MRI. In fact, the additional inclusion of the hypointensity on the HBP when there is no washout on portal venous or transient phase may increase its sensitivity for the diagnosis of HCC (Fig. 4) but at the cost of reduced specificity, mainly due to the pseudo-washout phenomenon $(30,31)$. However, since most false-positive diagnoses are caused by hemangiomas, CCs, and combined hepatocellularCCs from the use of the HBP for determining the washout appearance, applying the exclusion criteria for a targetoid appearance or marked T2 hyperintensity is expected to prevent a significant loss in specificity (30). In keeping with this prediction, Joo et al. (69) recently reported sensitivity of $92.5 \%$ and the specificity of $87.4 \%$ for the new diagnostic criteria after additionally encompassing hypointensity on HBP as an alternative washout after applying the exclusion criteria. In the study (69), the application of the exclusion criteria significantly improved the specificity ( $87.4 \%$ vs. 48.4\%) compared to the criteria without the exclusion criteria. Representative cases are presented in Figures 5 and 6. Furthermore, considering the widespread use of gadoxetic acid-enhanced MRI as well as most clinicians' preference for early diagnosis and treatment for HCCs in Korea, the KLCANCC Guidelines version 2018 adopt washout in the portal, transitional, or HBPs after applying these exclusion criteria.

Fourth, CEUS is now adopted as a secondary diagnostic test when a proper diagnosis of HCC is not made by initial 



A


Fig. 4. Gadoxetic acid-enhanced MRI in 62-year-old man with CHB.

On arterial phase MRI (A), 1.2-cm enhancing nodule is visualized in S4 (arrows) abutting middle hepatic vein. Nodule shows iso-, iso-, and hypointensity on portal (B); transitional (C); and hepatobiliary (D) phases, respectively. Lesion was pathologically confirmed as HCC. This nodule does not meet criteria of LR-5 according to Western guidelines; however, this nodule can be diagnosed as HCC according to updated 2018 KLCA-NCC guidelines.

diagnostic tests. Lastly, the updeted guidelines suggest separate diagnostic criteria for recurrent HCCs in order to increase sensitivity, considering the higher possibility of HCC development in patients with a history of HCC than those without HCC. For newly developed hepatic nodules or those with an interval size increase during followup in patients with a previous history of HCC, HCC can be diagnosed if they show compatible ancillary imaging features, even without typical imaging features.

\section{Comparison between KLCA-NCC Practice Guidelines Version 2018 and Other Guidelines}

Comparisons of the KLCA-NCC practice guidelines version 2018 with the 2018 AASLD and EASL guidelines, as well as with 2018 LI-RADS and with 2017 APASL, are summarized in Table 2. Compared to the previous guidelines, there have been changes in the diagnostic tests and in the decision algorithm. For example, the 2018 updated guidelines from EASL and AASLD now include gadoxetic acid-enhanced MRI as a diagnostic test, while the new EASL and KLCA guidelines now include CEUS as a second-line diagnostic test.

The KLCA-NCC guidelines share several similarities with other guidelines including AASLD, EASL, LI-RADS, and APASL, i.e., the usage of gadoxetic acid-enhanced MRI as a diagnostic examination with only one diagnostic test required. The KLCA-NCC guidelines also use ancillary findings as exclusion criteria to preserve specificity, similar to AASLD or LI-RADS. As for the target population for surveillance, they are generally similar but they do have 


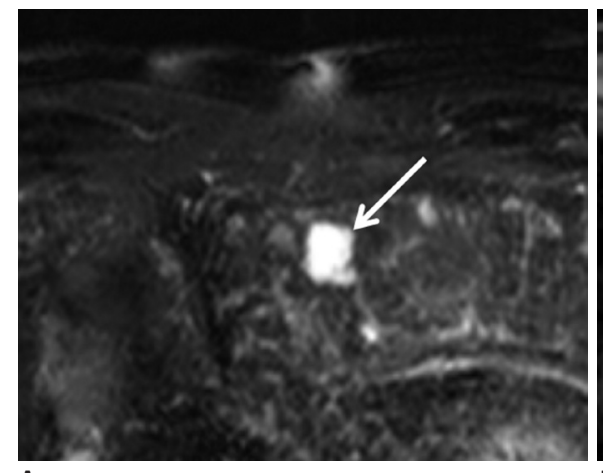

A



D

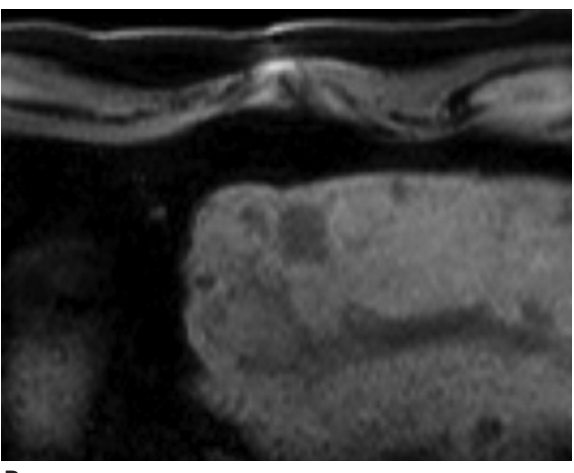

B

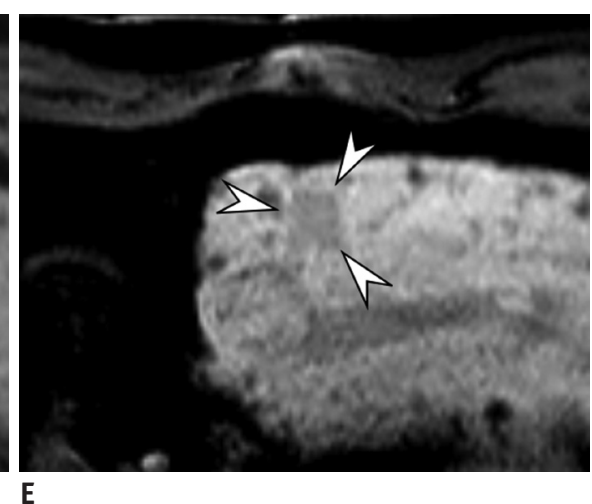



C

Fig. 5. Gadoxetic acid-enhanced MRI in 70-year-old man with CHB.

On T2-weighted (A) and precontrast T1-weighted (B) MRI, 2-cm nodule (arrow) is seen with marked T2 hyperintensity and low T1 SI at subcapsular portion of segment 2 of liver. After contrast injection, lesion demonstrates nodular enhancement in arterial phase (C) and persistent enhancement in portal phase (D). Lesion (arrowheads) depicts hypointensity on HBP (E). Lesion was proved to be hemangioma by showing no interval change over years. Regardless of arterial enhancement with hepatobiliary defect, diagnosis of HCC cannot be made due to exclusion criteria of marked T2 hyperintensity according to updated KLCA-NCC guidelines version 2018.

a slight difference: the KLCA-NCC guidelines include liver cirrhosis of any cause and chronic hepatitis B or C virus infections whereas AASLD and EASL include only patients with liver cirrhosis and chronic hepatitis B. Furthermore, regarding washout timing, the KLCA-NCC and APASL guidelines include the HBP whereas AASLD, EASL, and LIRADS use only the portal venous phase. Finally, a definite diagnosis for subcentimeter HCCs or hypovascular HCCs, at present, is only possible with the APASL guideline.

Major discrepancies between the guidelines of Western societies such as AASLD, EASL, LI-RADS and those from Eastern societies such as KLCA-NCC and APASL, are mainly attributed to different priorities in treatment practices between the two geographic areas with different diagnostic scopes $(10,70)$. For instance, the new diagnostic criterion for additionally encompassing hypointensity on HBP as an alternative washout after applying the exclusion criteria in KLCA-NCC guidelines version 2018 results in a relatively higher sensitivity of $92.5 \%$ but comparable or slightly lower specificity of $87.4 \%$ (69), compared to those in previous studies (sensitivity, 60.5-83.5\%; specificity, 81.2-100\%) (31, 71-73) which evaluated the criterion of APHE plus hypointensity only on the portal venous phase in gadoxeticacid-enhanced MRI (equivalent to the hypervascular HCC diagnostic criterion used in EASL and LI-RADS). In Europe and USA, the diagnostic criteria are intentionally designed to achieve high specificity rather than high sensitivity for the diagnosis of a definite HCC while diagnostic criteria favor high sensitivity for the detection of early HCCs in Asia. This differences in practice patterns are related to the preference between liver transplantation versus locoregional ablative therapies for the management of patients with early-stage HCCs $(10,37)$.

Regardless of the region, another difference among the guidelines could be the preference toward binary versus non-binary decisions with different diagnostic scopes. At present, LI-RADS, AASLD, and KLCA-NCC use a nonbinary decision algorithm covering the whole spectrum of observations seen in the liver whereas other systems including EASL and APASL use binary decisions mainly 


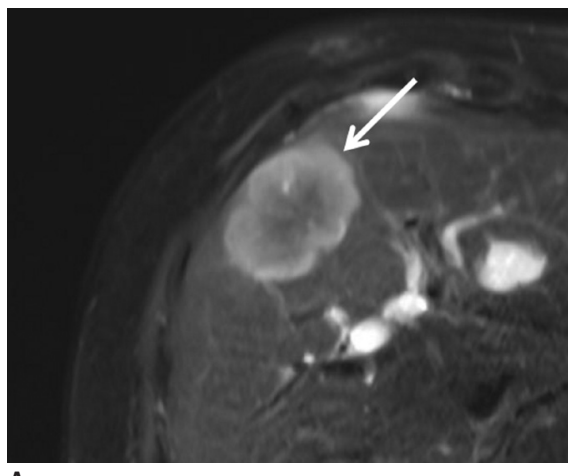

A

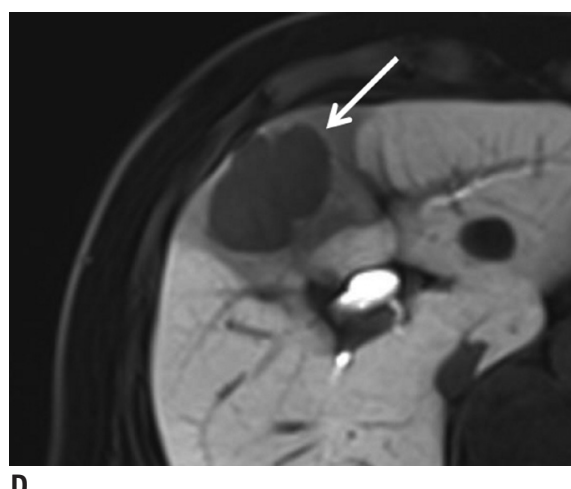

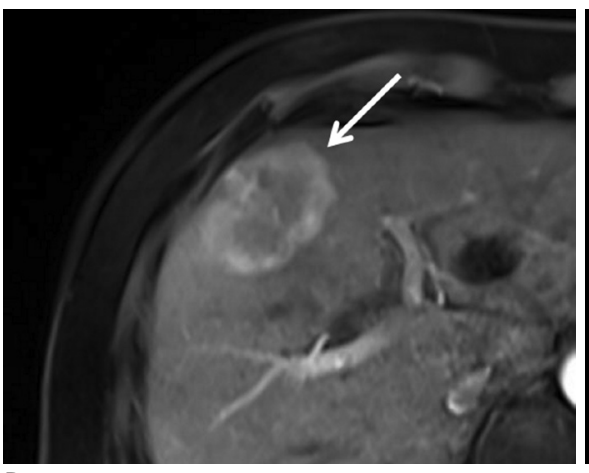

B

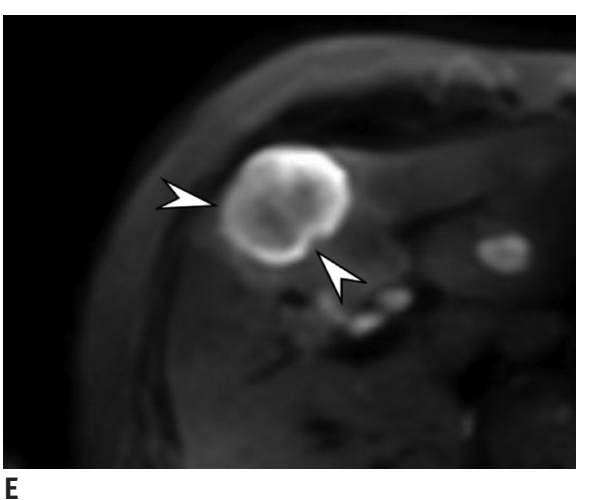

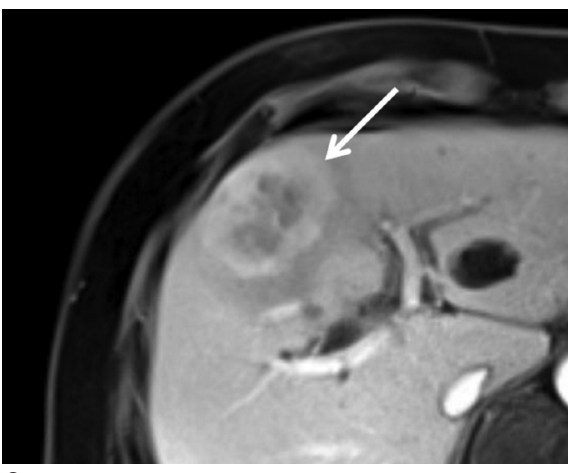

C

Fig. 6. Gadoxetic acid-enhanced MRI in 70-year-old woman with chronic hepatitis $\mathrm{C}$.

On fat-saturated T2-weighted image (A), approximately 5-cm mass (arrow) with mild hyperintensity is seen in segment 4 of liver. After gadoxetic acid injection, lesion (arrows) shows arterial hyperenhancement (B), isointensity on portal phase (C), and hypointensity on HBP (D). On diffusion-weighted image (E), mass (arrowheads) demonstrates peripheral hyperintensity with typical targetoid appearance. Mass was histopathologically confirmed as cholangiocarcinoma. Regardless of presence of arterial enhancement with hepatobiliary defect, diagnosis of HCC cannot be made due to exclusion criteria of targetoid appearance according to updated KLCA-NCC guidelines version 2018.

focusing on the distinction between HCCs and nonHCCs. Furthermore, EASL, AASLD, LI-RADS, and KLCA-NCC guidelines allow a definite HCC diagnosis only for HCCS with APHE while the APASL guideline provides criteria for both hypervascular and hypovascular HCCs. Finally, only the APASL guideline allows for a definite HCC diagnosis for subcentimeter nodules based on hallmark imaging features of $\mathrm{HCC}$.

\section{Unsolved Issues or Controversial Issues}

There are some unsolved or controversial issues that must be addressed. First, although both EASL and KLCA-NCC practice guidelines start the diagnostic flow with nodules detected at the imaging or surveillance test, the diagnostic flow in AASLD and APASL guidelines mainly depend on USdetected nodules to be initiated $(11,16,17)$. In brief, since US can be regarded as the most appropriate test for surveillance in many regions, the detection sensitivity of US for cirrhotic nodules $>1 \mathrm{~cm}$ may significantly affect the sensitivity of the diagnostic algorithm. However, the reported diagnostic accuracy of US when used as a surveillance test ranges between $58 \%$ and $89 \%$ in sensitivity, although its specificity is greater than $90 \%$ (74). One meta-analysis including 19 studies also revealed that US was less effective in detecting early-stage HCCs, with a sensitivity of only $63 \%$ (75). Furthermore, the diagnostic performance of US could be limited in patients with truncal obesity or marked parenchymal heterogeneity owing to cirrhosis (75). According to AASLD, EASL, and KLCA-NCC practice guidelines, $\mathrm{CT}$ and MRI are not recommended as the primary modalities for the surveillance of HCC in every cirrhotic patient due to the paucity of data on its efficacy and cost-effectiveness. However, in select patients with a high likelihood of having an inadequate US or if ultrasound is attempted but inadequate, CT, MRI, or CEUS may be utilized as an alternative tool to the US examination. Indeed, according to a recent cohort study enrolling 407 cirrhotic patients in which US and HBCM-enhanced MRI were compared for the surveillance of HCC, MRI showed 
Table 2. Comparison of KLCA-NCC, APASL, AASLD, LI-RADS, and EASL Guidelines

\begin{tabular}{|c|c|c|c|c|c|}
\hline & KLCA-NCC 2018 & APASL 2017 & AASLD 2018 & LI-RADS 2018 & EASL 2018 \\
\hline Target population & $\begin{array}{l}\mathrm{CHB}, \mathrm{CHC}, \mathrm{LC} \text { of any } \\
\text { cause }\end{array}$ & $\begin{array}{l}\text { All patients at high } \\
\text { risk for HCC }\end{array}$ & LC of any cause & $\begin{array}{l}\text { CHB, LC of any } \\
\text { cause, patients } \\
\text { with current or } \\
\text { prior HCC }\end{array}$ & LC of any cause \\
\hline Target lesion & $\begin{array}{c}\text { Detected nodule at } \\
\text { surveillance test } \\
\text { (CT/MR detected } \\
\text { nodule in select } \\
\text { patients*) }\end{array}$ & US detected nodule & $\begin{array}{l}\text { US detected nodule } \\
\text { (CT/MR detected } \\
\text { nodule in select } \\
\text { patients*) }\end{array}$ & All nodules & $\begin{array}{l}\text { Mass/nodule at } \\
\text { imaging }\end{array}$ \\
\hline $\begin{array}{l}\text { Primary imaging } \\
\text { modality }\end{array}$ & $\begin{array}{l}\text { CT, MRI using ECCM } \\
\text { or HBCM }\end{array}$ & $\begin{array}{l}\text { CT, MRI using ECCM } \\
\text { or HBCM }\end{array}$ & $\begin{array}{l}\mathrm{CT} \text {, MRI using ECCM } \\
\quad \text { or } \mathrm{HBCM}\end{array}$ & $\begin{array}{l}\text { CT, MRI using ECCM } \\
\text { or } \mathrm{HBCM}, \mathrm{CEUS}^{\dagger}\end{array}$ & $\begin{array}{l}\mathrm{CT} \text {, MRI using ECCM } \\
\text { or HBCM }\end{array}$ \\
\hline $\begin{array}{l}\text { Secondary imaging } \\
\text { modality }\end{array}$ & $\begin{array}{l}\text { Yes } \\
\text { - CEUS }\end{array}$ & $\begin{array}{l}\text { Yes } \\
\text { - CEUS (Sonazoid }{ }^{\ddagger} \text { ) }\end{array}$ & No & No & $\begin{array}{l}\text { Yes } \\
\text { - } \text { CEUS }^{\dagger}\end{array}$ \\
\hline Diagnostic hallmark & $\begin{array}{l}\text { Nodule size }>1 \mathrm{~cm} \\
\text { APHE } \\
\text { Washout on PVP/DP } \\
\text { Washout on PVP/TP } \\
\text { or hypointensity on } \\
\text { HBP, when HBCM is } \\
\text { used }\end{array}$ & $\begin{array}{l}\text { 1) Dynamic CT/MR } \\
\text { APHE } \\
\text { Washout on PVP/DP } \\
\text { 2) HBCM MRI } \\
\text { (a) APHE, washout } \\
\text { on PVP } \\
\text { (b) APHE, no } \\
\text { washout on PVP } \\
+ \text { hypointensity } \\
\text { on HBP } \\
\text { (c) No APHE + } \\
\text { hypointensity } \\
\text { on HBP + APHE } \\
\text { \& Kupffer phase } \\
\text { defects on CEUS } \\
\text { (Sonazoid }{ }^{\ddagger} \text { ) }\end{array}$ & $\begin{array}{l}\text { Nodule size > } 1 \mathrm{~cm} \\
\text { APHE } \\
\text { Washout on PVP/DP } \\
\text { Washout on PVP, } \\
\text { when HBCM is } \\
\text { used }\end{array}$ & $\begin{array}{l}\text { Nodule size }>1 \mathrm{~cm} \\
\text { 1) Dynamic CT, MRI } \\
\text { using ECCM or } \\
\text { HBCM } \\
\text { APHE } \\
\text { Washout on PVP/DP } \\
\text { Washout on } \\
\text { PVP, when } \\
\text { HBCM is used } \\
\text { enhancing } \\
\text { capsule } \\
\text { Threshold growth } \\
\text { 2) CEUS } \\
\text { APHE } \\
\text { Late (> } 60 \text { s) and } \\
\text { mild washout }\end{array}$ & $\begin{array}{l}\text { Nodule size > } 1 \mathrm{~cm} \\
\text { APHE } \\
\text { Washout on PVP/DP } \\
\text { Washout on PVP, } \\
\text { when HBCM is } \\
\text { used }\end{array}$ \\
\hline Ancillary findings & $\begin{array}{l}\text { Yes } \\
\text { - Intermediate high SI } \\
\text { on T2WI, high SI on } \\
\text { DWI, and interval } \\
\text { growth on follow-up } \\
\text { imaging } \\
\text { - Presence of capsule, } \\
\text { mosaic appearance, } \\
\text { nodule-in-nodule } \\
\text { appearance, } \\
\text { intratumoral fat or } \\
\text { hemorrhage }\end{array}$ & No & $\begin{array}{l}\text { Yes } \\
\text { - Up scoring } \\
\quad \text { (up to LR-4) } \\
\text { - Down scoring }\end{array}$ & $\begin{array}{l}\text { Yes } \\
\text { - Up scoring } \\
\quad \text { (up to LR-4) } \\
\text { - Down scoring }\end{array}$ & No \\
\hline Exclusion criteria & $\begin{array}{l}\text { Yes } \\
\text { When HBCM is used } \\
\text { - T2 bright SI } \\
\text { - Targetoid appearance } \\
\text { in DWI or CE-T1WI }\end{array}$ & No & No & No & No \\
\hline $\begin{array}{c}\text { Number of required } \\
\text { examinations }\end{array}$ & 1 & 1 & 1 & 1 & 1 \\
\hline Tumor marker (AFP) & $\mathrm{N} / \mathrm{A}$ & $\mathrm{N} / \mathrm{A}$ & $\mathrm{N} / \mathrm{A}$ & $\mathrm{N} / \mathrm{A}$ & $\mathrm{N} / \mathrm{A}$ \\
\hline
\end{tabular}


Updated Korean Guidelines for Non-Invasive HCC Diagnosis and Unsolved Issues

Table 2. Comparison of KLCA-NCC, APASL, AASLD, LI-RADS, and EASL Guidelines (Continued)

\begin{tabular}{|c|c|c|c|c|c|}
\hline & KLCA-NCC 2018 & APASL 2017 & AASLD 2018 & LI-RADS 2018 & EASL 2018 \\
\hline \multirow[t]{14}{*}{ Category } & $\mathrm{HCC}$ & $\mathrm{HCC}$ & Benign (LR-1) & Benign (LR-1) & $\mathrm{HCC}$ \\
\hline & Probable HCC & Non-HCC & Probably benign & Probably benign & Non-HCC \\
\hline & Indeterminate & & (LR-2) & (LR-2) & \\
\hline & & & Indeterminate & Indeterminate & \\
\hline & & & $(\mathrm{LR}-3)$ & $($ LR-3) & \\
\hline & & & Probably HCC & Probably HCC & \\
\hline & & & $(L R-4)$ & $(L R-4)$ & \\
\hline & & & Definitely HCC & Definitely HCC & \\
\hline & & & $(L R-5)$ & $(L R-5)$ & \\
\hline & & & Malignancy, not & Tumor in vein & \\
\hline & & & definitely $\mathrm{HCC}$ & (LR-TIV) & \\
\hline & & & (LR-M) & Malignancy, not & \\
\hline & & & & definitely HCC & \\
\hline & & & & $($ LR-M) & \\
\hline Noninvasive & No & Yes & No & No & No \\
\hline diagnosis of & & & & & \\
\hline subcentimeter HCC & & & & & \\
\hline Nonivasive diagnosis & No & Yes & No & No & No \\
\hline of hypovascular & & & & & \\
\hline $\mathrm{HCC}$ & & & & & \\
\hline
\end{tabular}

* Some high-risk patients may undergo multiphase CT or MRI for HCC surveillance (depending on patient body habitus, visibility of liver at ultrasound, being on transplant waiting list and other factors), 'Pure blood-pool contrast agents, 'Sonazoid; GE Healthcare. AASLD $=$ Association for Study of Liver Diseases, AFP = alpha-fetoprotein, APASL = Asian-Pacific Association for Study of Liver, DP = delayed phase, $\mathrm{DWI}=$ diffusion-weighted imaging, $\mathrm{EASL}=$ European Association for Study of Liver, ECCM $=$ extracellular contrast media, $\mathrm{HBCM}=$ hepatobiliary contrast media, LC = liver cirrhosis, LI-RADS = Liver Imaging Reporting and Data System, MR = magnetic resonance, N/A = not applicable, PVP = portal venous phase, SI = signal intensity, TIV = tumor in vein, TP = transitional phase, T1WI = T1-weighted image, T2WI $=$ T2-weighted image

significantly higher sensitivity and a lower false-positive rate compared with US (75). More recently, abbreviated MRI examination protocols showed similar sensitivity to screening US but with a significantly lower false-positive rate $(76,77)$. In addition, a previous simulation study by Tanaka et al. (78) demonstrated that CEUS surveillance for HCC could be a cost-effective strategy for cirrhotic patients in the US surveillance group. However, even under these circumstances, the radiation risk due to repeated CT scans, high cost of MR, and the need for contrast injection make their use in long-term surveillance highly debatable. Further studies are warranted to define conditions in which either CT, MRI, or CEUS can be additionally used for the surveillance of HCC.

Second, it is not possible to make a definite diagnosis of $\mathrm{HCC}$ for small $(<1 \mathrm{~cm})$ nodules according to most guidelines except APASL due to the low probability of HCC in lesions $<1 \mathrm{~cm}$ and the difficulty of making a reliable diagnosis for small nodules on CT or MRI $(28,70)$. Currently, only APASL allows a noninvasive diagnosis of HCC for small nodules $<1 \mathrm{~cm}$ when they show the hallmark imaging features of
HCC on CT or MRI. In addition, according to LI-RADS, for subcentimeter nodules that show arterial hyperenhancement along with one of three major findings such as "washout," "capsule," or "threshold growth," they can be considered to be LR-4 (probably HCC) (19). Furthermore, considering the high progression rate $(89.9-100 \%)$ of subcentimeter hypervascular nodules showing typical HCC imaging findings on gadoxetic acid-enhanced MRI to typical HCCs in patients with a history of treatment for $\operatorname{HCC}(36,79)$ and the improved prognosis of very early-stage HCCs compared to early-stage HCCs $(70,80)$, the diagnosis of subcentimeter $\mathrm{HCCS}$ in patients with a history of treatment for HCC is possible according to the KLCA-NCC version 2018 guidelines. Thus, with diverse opinions on acknowledging the diagnosis of subcentimeter HCCs among guidelines, further studies are warranted to better refine the diagnostic criteria and to better stratify the degree of risk in subcentimeter nodules.

Third, there is no concrete evidence as to which modality would be the most proper secondary imaging modality when imaging findings on the initial modality are inconclusive. Although there has been a trend toward the utilization of 
CEUS as the secondary modality, as endorsed by EASL, KLCANCC, and APASL guidelines, AASLD guidelines still doubt the feasibility of CEUS owing to its operator dependency, lack of generalizability with regional variations in Asian versus Western countries, as well as the absence of a large-scale study. Therefore, further prospective studies involving a larger number of patients are warranted to confirm the role of CEUS as the most effective secondary modality.

Lastly, different contrast agents such as Sonazoid and SonoVue are recommended for CEUS according to the guidelines; Sonazoid is only used in JSH and APASL guidelines. The Kupffer-phase CEUS that can be additionally provided with Sonazoid may provide better sensitivity in the detection of focal hepatic nodules, but may suffer from low specificity for the diagnosis of HCC as other entities such as hemangiomas or CCs also lack Kupffer cells. This limitation of CEUS with Sonazoid is similar to the obstacle faced with HBCM-enhanced MRI. Although defect reperfusion imaging with Sonazoid, which allow reinjection of Sonazoid into areas showing defects in Kupffer phase, may improve the specificity for the diagnosis of $\operatorname{HCCs}(45,81)$, further studies are warranted to clarify the diagnostic power between the two CEUS agents.

\section{CONCLUSION}

In the last 2 years, several major guidelines of HCC have been updated. Key changes in those guidelines are the addition of HBCM-enhanced MRI as the first-line diagnostic test or inclusion of CEUS as the second-line diagnostic test. These changes will have a profound clinical impact on both diagnosis and characterization of hepatic nodules in patients at high risk, and it can also be expected that HBCM-enhanced MRI and CEUS will play an increasing role for the noninvasive diagnosis of HCC in the years to come. Although the noninvasive diagnostic criteria of dynamic CT and MRI with ECCM endorsed by the major guidelines are in good agreement, discrepancies still do exist in the diagnostic criteria of MRI using HBCM. Furthermore, several issues remain to be solved regarding the diagnostic accuracy of US surveillance, diagnosis of subcentimeter HCCs and hypovascular HCCs, the most appropriate secondary imaging modality, and the effect of different CEUS contrast agents (SonoVue and Sonazoid). We hope that these issues can be clearly resolved on the basis of large-scale data-driven evidence, in the near future.

\section{Conflicts of Interest}

The authors have no potential conflicts of interest to disclose.

\section{ORCID iDs}

Jeong Min Lee

https://orcid.org/0000-0003-0561-8777

Tae-Hyung Kim

https://orcid.org/0000-0002-0333-8475

\section{REFERENCES}

1. Choo SP, Tan WL, Goh BKP, Tai WM, Zhu AX. Comparison of hepatocellular carcinoma in Eastern versus Western populations. Cancer 2016;122:3430-3446

2. Altekruse SF, McGlynn KA, Reichman ME. Hepatocellular carcinoma incidence, mortality, and survival trends in the United States from 1975 to 2005. J Clin Oncol 2009;27:14851491

3. Singal AG, Pillai A, Tiro J. Early detection, curative treatment, and survival rates for hepatocellular carcinoma surveillance in patients with cirrhosis: a meta-analysis. PLoS Med 2014;11:e1001624

4. Trevisani F, De Notariis S, Rapaccini G, Farinati F, Benvegnù L, Zoli $M$, et al. Semiannual and annual surveillance of cirrhotic patients for hepatocellular carcinoma: effects on cancer stage and patient survival (Italian experience). Am J Gastroenterol 2002;97:734-744

5. Ando E, Kuromatsu R, Tanaka M, Takada A, Fukushima N, Sumie $S$, et al. Surveillance program for early detection of hepatocellular carcinoma in Japan: results of specialized department of liver disease. J Clin Gastroenterol 2006;40:942948

6. Noda I, Kitamoto M, Nakahara H, Hayashi R, Okimoto T, Monzen $Y$, et al. Regular surveillance by imaging for early detection and better prognosis of hepatocellular carcinoma in patients infected with hepatitis C virus. J Gastroenterol 2010;45:105-112

7. Lopez PM, Villanueva A, Llovet JM. Systematic review: evidence-based management of hepatocellular carcinoma-an updated analysis of randomized controlled trials. Aliment Pharmacol Ther 2006;23:1535-1547

8. Cruite I, Tang A, Sirlin CB. Imaging-based diagnostic systems for hepatocellular carcinoma. AJR Am J Roentgenol 2013;201:41-55

9. Tang A, Cruite I, Sirlin CB. Toward a standardized system for hepatocellular carcinoma diagnosis using computed tomography and MRI. Expert Rev Gastroenterol Hepatol 2013;7:269-279

10. Tang A, Cruite I, Mitchell DG, Sirlin CB. Hepatocellular carcinoma imaging systems: why they exist, how they have evolved, and how they differ. Abdom Radiol (NY) 2018;43:3- 
Updated Korean Guidelines for Non-Invasive HCC Diagnosis and Unsolved Issues

12

11. Heimbach JK, Kulik LM, Finn RS, Sirlin CB, Abecassis MM, Roberts LR, et al. AASLD guidelines for the treatment of hepatocellular carcinoma. Hepatology 2018;67:358-380

12. Yu JS, Kim KW, Kim EK, Lee JT, Yoo HS. Contrast enhancement of small hepatocellular carcinoma: usefulness of three successive early image acquisitions during multiphase dynamic MR imaging. AJR Am J Roentgenol 1999;173:597-604

13. Torzilli G, Minagawa M, Takayama T, Inoue K, Hui AM, Kubota $K$, et al. Accurate preoperative evaluation of liver mass lesions without fine-needle biopsy. Hepatology 1999;30:889-893

14. Choi JY, Lee JM, Sirlin CB. CT and MR imaging diagnosis and staging of hepatocellular carcinoma: part I. Development, growth, and spread: key pathologic and imaging aspects. Radiology 2014;272:635-654

15. Marrero JA, Kulik LM, Sirlin CB, Zhu AX, Finn RS, Abecassis MM, et al. Diagnosis, staging and management of hepatocellular carcinoma: 2018 practice guidance by the American association for the study of liver diseases. Hepatology 2018;68:723-750

16. European Association for the Study of the Liver. EASL clinical practice guidelines: management of hepatocellular carcinoma. J Hepatol 2018;69:182-236

17. Omata M, Cheng AL, Kokudo N, Kudo M, Lee JM, Jia J, et al. Asia-pacific clinical practice guidelines on the management of hepatocellular carcinoma: a 2017 update. Hepatol Int 2017;11:317-370

18. CT/MRI LI-RADS ${ }^{\circledR}$, version 2017. American College of Radiology Web site. https://www.acr.org/Clinical-Resources/ Reporting-and-Data-Systems/LI-RADS/CT-MRI-LI-RADS-v2017, Accessed April 3, 2019

19. New: CT/MRI LI-RADS ${ }^{\circledR}$, version 2018. American College of Radiology Web site. https://www.acr.org/Clinical-Resources/ Reporting-and-Data-Systems/LI-RADS/CT-MRI-LI-RADS-v2018, Accessed April 3, 2019

20. Wald C, Russo MW, Heimbach JK, Hussain HK, Pomfret EA, Bruix J. New OPTN/UNOS policy for liver transplant allocation: standardization of liver imaging, diagnosis, classification, and reporting of hepatocellular carcinoma. Radiology 2013;266:376-382

21. Kudo M, Matsui 0, Izumi N, Iijima H, Kadoya M, Imai $Y$, et al. JSH consensus-based clinical practice guidelines for the management of hepatocellular carcinoma: 2014 update by the liver cancer study group of Japan. Liver Cancer 2014;3:458468

22. Korean Liver Cancer Study Group (KLCSG), National Cancer Center, Korea (NCC). 2014 Korean Liver Cancer Study GroupNational Cancer Center Korea practice guideline for the management of hepatocellular carcinoma. Korean J Radiol 2015; 16:465-522

23. Gavriilidis P, Roberts KJ, Askari A, Sutcliffe RP, Huo TL, Liu $\mathrm{PH}$, et al. Evaluation of the current guidelines for resection of hepatocellular carcinoma using the appraisal of guidelines for research and evaluation II instrument. J Hepatol 2017;
67:991-998

24. Korean Liver Cancer Association and National Cancer Center (KLCA-NCC) Korea. 2018 Korean liver cancer associationnational cancer center Korea practice guidelines for management of hepatocellular carcinoma. Gut Liver 2019;13:227-299

25. Choi JY, Lee JM, Sirlin CB. CT and MR imaging diagnosis and staging of hepatocellular carcinoma: part II. Extracellular agents, hepatobiliary agents, and ancillary imaging features. Radiology 2014;273:30-50

26. Kitao A, Matsui 0, Yoneda N, Kozaka K, Shinmura R, Koda $W$, et al. The uptake transporter 0ATP8 expression decreases during multistep hepatocarcinogenesis: correlation with gadoxetic acid enhanced MR imaging. Eur Radiol 2011;21:2056-2066

27. Kogita S, Imai Y, Okada M, Kim T, Onishi H, Takamura M, et al. Gd-EOB-DTPA-enhanced magnetic resonance images of hepatocellular carcinoma: correlation with histological grading and portal blood flow. Eur Radiol 2010;20:2405-2413

28. Lee YJ, Lee JM, Lee JS, Lee HY, Park BH, Kim YH, et al. Hepatocellular carcinoma: diagnostic performance of multidetector CT and MR imaging-a systematic review and meta-analysis. Radiology 2015;275:97-109

29. Kim HD, Lim YS, Han S, An J, Kim GA, Kim SY, et al. Evaluation of early-stage hepatocellular carcinoma by magnetic resonance imaging with gadoxetic acid detects additional lesions and increases overall survival. Gastroenterology 2015;148:1371-1382

30. Joo I, Lee JM, Lee DH, Jeon JH, Han JK, Choi BI. Noninvasive diagnosis of hepatocellular carcinoma on gadoxetic acidenhanced MRI: can hypointensity on the hepatobiliary phase be used as an alternative to washout? Eur Radiol 2015;25:2859-2868

31. Choi SH, Byun JH, Lim YS, Yu E, Lee SJ, Kim SY, et al. Diagnostic criteria for hepatocellular carcinoma $3 \mathrm{~cm}$ with hepatocyte-specific contrast-enhanced magnetic resonance imaging. J Hepatol 2016;64:1099-1107

32. Sangiovanni A, Manini MA, Iavarone M, Romeo R, Forzenigo LV, Fraquelli $M$, et al. The diagnostic and economic impact of contrast imaging techniques in the diagnosis of small hepatocellular carcinoma in cirrhosis. Gut 2010;59:638-644

33. Khalili K, Kim TK, Jang HJ, Haider MA, Khan L, Guindi M, et al. Optimization of imaging diagnosis of $1-2 \mathrm{~cm}$ hepatocellular carcinoma: an analysis of diagnostic performance and resource utilization. J Hepatol 2011;54:723-728

34. Yoon JH, Park JW, Lee JM. Noninvasive diagnosis of hepatocellular carcinoma: elaboration on Korean Liver Cancer Study Group-National Cancer Center Korea practice guidelines compared with other guidelines and remaining issues. Korean J Radiol 2016;17:7-24

35. Korean Society of Abdominal Radiology. Diagnosis of hepatocellular carcinoma with gadoxetic acid-enhanced MRI: 2016 consensus recommendations of the Korean Society of Abdominal Radiology. Korean J Radiol 2017;18:427-443 
36. Song KD, Kim SH, Lim HK, Jung SH, Sohn I, Kim HS. Subcentimeter hypervascular nodule with typical imaging findings of hepatocellular carcinoma in patients with history of hepatocellular carcinoma: natural course on serial gadoxetic acid-enhanced MRI and diffusion-weighted imaging. Eur Radiol 2015;25:2789-2796

37. Yoon JH, Lee JM, Yang HK, Lee KB, Jang JJ, Han JK, et al. Non-hypervascular hypointense nodules $\geq 1 \mathrm{~cm}$ on the hepatobiliary phase of gadoxetic acid-enhanced magnetic resonance imaging in cirrhotic livers. Dig Dis 2014;32:678689

38. Choi JW, Lee JM, Kim SJ, Yoon JH, Baek JH, Han JK, et al. Hepatocellular carcinoma: imaging patterns on gadoxetic acid-enhanced MR images and their value as an imaging biomarker. Radiology 2013;267:776-786

39. Suh YJ, Kim MJ, Choi JY, Park YN, Park MS, Kim KW. Differentiation of hepatic hyperintense lesions seen on gadoxetic acid-enhanced hepatobiliary phase MRI. AJR Am J Roentgenol 2011;197:W44-W52

40. Davenport MS, Viglianti BL, AL-Hawary MM, Caoili EM, Kaza RK, Liu PS, et al. Comparison of acute transient dyspnea after intravenous administration of gadoxetate disodium and gadobenate dimeglumine: effect on arterial phase image quality. Radiology 2013;266:452-461

41. Pietryga JA, Burke LM, Marin D, Jaffe TA, Bashir MR. Respiratory motion artifact affecting hepatic arterial phase imaging with gadoxetate disodium: examination recovery with a multiple arterial phase acquisition. Radiology 2014;271:426434

42. Bolondi L, Correas JM, Lencioni R, Weskott HP, Piscaglia F. New perspectives for the use of contrast-enhanced liver ultrasound in clinical practice. Dig Liver Dis 2007;39:187-195

43. Strobel D, Bernatik T, Blank W, Schuler A, Greis C, Dietrich CF, et al. Diagnostic accuracy of CEUS in the differential diagnosis of small $(\leq 20 \mathrm{~mm})$ and subcentimetric $(\leq 10 \mathrm{~mm}$ ) focal liver lesions in comparison with histology. Results of the DEGUM multicenter trial. Ultraschall Med 2011;32:593-597

44. Kim TK, Noh SY, Wilson SR, Kono Y, Piscaglia F, Jang HJ, et al. Contrast-enhanced ultrasound (CEUS) liver imaging reporting and data system (LI-RADS) 2017 - a review of important differences compared to the CT/MRI system. Clin Mol Hepatol 2017;23:280-289

45. Kudo M. Defect reperfusion imaging with Sonazoid ${ }^{\circledR}$ : a breakthrough in hepatocellular carcinoma. Liver Cancer 2016;5:1-7

46. Maruyama H, Takahashi M, Ishibashi H, Yoshikawa M, Yokosuka 0. Contrast-enhanced ultrasound for characterisation of hepatic lesions appearing non-hypervascular on $\mathrm{CT}$ in chronic liver diseases. Br J Radiol 2012;85:351-357

47. Takahashi M, Maruyama H, Shimada T, Kamezaki H, Sekimoto $T$, Kanai $F$, et al. Characterization of hepatic lesions $(\leq 30 \mathrm{~mm})$ with liver-specific contrast agents: a comparison between ultrasound and magnetic resonance imaging. Eur J Radiol 2013;82:75-84
48. Wilson SR, Kim TK, Jang HJ, Burns PN. Enhancement patterns of focal liver masses: discordance between contrast-enhanced sonography and contrast-enhanced CT and MRI. AJR Am J Roentgenol 2007;189:W7-W12

49. Itai Y, Furui S, Ohtomo K, Kokubo T, Yamauchi T, Minami $M$, et al. Dynamic CT features of arterioportal shunts in hepatocellular carcinoma. AJR Am J Roentgenol 1986;146:723727

50. Yu JS, Kim KW, Jeong MG, Lee JT, Yoo HS. Nontumorous hepatic arterial-portal venous shunts: MR imaging findings. Radiology 2000;217:750-756

51. Leoni S, Piscaglia F, Granito A, Borghi A, Galassi M, Marinelli $S$, et al. Characterization of primary and recurrent nodules in liver cirrhosis using contrast-enhanced ultrasound: which vascular criteria should be adopted? Ultraschall Med 2013;34:280-287

52. Claudon M, Dietrich CF, Choi BI, Cosgrove D0, Kudo M, Nolsøe $C P$, et al. Guidelines and good clinical practice recommendations for contrast enhanced ultrasound (CEUS) in the liver--update 2012: a WFUMB-EFSUMB initiative in cooperation with representatives of AFSUMB, AIUM, ASUM, FLAUS and ICUS. Ultraschall Med 2013;34:11-29

53. Bota S, Piscaglia F, Marinelli S, Pecorelli A, Terzi E, Bolondi L. Comparison of international guidelines for noninvasive diagnosis of hepatocellular carcinoma. Liver Cancer 2012; 1:190-200

54. Italian Association for the Study of the Liver (AISF); AISF Expert Panel; AISF Coordinating Committee; Bolondi $L$, Cillo U, Colombo M, Craxi A, Farinati F, Giannini EG, et al. Position paper of the Italian association for the study of the liver (AISF): the multidisciplinary clinical approach to hepatocellular carcinoma. Dig Liver Dis 2013;45:712-723

55. Sherman M, Burak K, Maroun J, Metrakos P, Knox JJ, Myers RP, et al. Multidisciplinary Canadian consensus recommendations for the management and treatment of hepatocellular carcinoma. Curr Oncol 2011;18:228-240

56. Furlan A, Marin D, Cabassa P, Taibbi A, Brunelli E, Agnello $F$, et al. Enhancement pattern of small hepatocellular carcinoma (HCC) at contrast-enhanced us (CEUS), MDCT, and MRI: intermodality agreement and comparison of diagnostic sensitivity between 2005 and 2010 American Association for the Study of Liver Diseases (AASLD) guidelines. Eur J Radiol 2012;81:2099-2105

57. Forner A, Vilana R, Ayuso C, Bianchi L, Solé M, Ayuso JR, et al. Diagnosis of hepatic nodules $20 \mathrm{~mm}$ or smaller in cirrhosis: prospective validation of the noninvasive diagnostic criteria for hepatocellular carcinoma. Hepatology 2008;47:97-104

58. Terzi E, Iavarone M, Pompili M, Veronese L, Cabibbo G, Fraquelli $M$, et al. Contrast ultrasound LI-RADS LR-5 identifies hepatocellular carcinoma in cirrhosis in a multicenter restropective study of 1,006 nodules. J Hepatol 2018;68:485492

59. Galassi M, Iavarone M, Rossi S, Bota S, Vavassori S, Rosa $L$, et al. Patterns of appearance and risk of misdiagnosis 
Updated Korean Guidelines for Non-Invasive HCC Diagnosis and Unsolved Issues

of intrahepatic cholangiocarcinoma in cirrhosis at contrast enhanced ultrasound. Liver Int 2013;33:771-779

60. Vilana R, Forner A, Bianchi L, García-Criado A, Rimola J, de Lope $C R$, et al. Intrahepatic peripheral cholangiocarcinoma in cirrhosis patients may display a vascular pattern similar to hepatocellular carcinoma on contrast-enhanced ultrasound. Hepatology 2010;51:2020-2029

61. Li R, Zhang X, Ma KS, Li XW, Xia F, Zhong H, et al. Dynamic enhancing vascular pattern of intrahepatic peripheral cholangiocarcinoma on contrast-enhanced ultrasound: the influence of chronic hepatitis and cirrhosis. Abdom Imaging 2013;38:112-119

62. Chen LD, Xu HX, Xie XY, Xie XH, Xu ZF, Liu GJ, et al. Intrahepatic cholangiocarcinoma and hepatocellular carcinoma: differential diagnosis with contrast-enhanced ultrasound. Eur Radiol 2010;20:743-753

63. Wildner D, Bernatik T, Greis C, Seitz K, Neurath MF, Strobel D. CEUS in hepatocellular carcinoma and intrahepatic cholangiocellular carcinoma in 320 patients - early or late washout matters: a subanalysis of the DEGUM multicenter trial. Ultraschall Med 2015;36:132-139

64. Wildner D, Pfeifer L, Goertz RS, Bernatik T, Sturm J, Neurath MF, et al. Dynamic contrast-enhanced ultrasound (DCE-US) for the characterization of hepatocellular carcinoma and cholangiocellular carcinoma. Ultraschall Med 2014;35:522-527

65. Piscaglia F, Kudo M, Han KH, Sirlin C. Diagnosis of hepatocellular carcinoma with non-invasive imaging: a plea for worldwide adoption of standard and precise terminology for describing enhancement criteria. Ultraschall Med 2017;38:9-11

66. Piscaglia F, Wilson SR, Lyshchik A, Cosgrove D, Dietrich $\mathrm{CF}$, Jang HJ, et al. American College of Radiology Contrast enhanced ultrasound Liver Imaging Reporting and Data System (CEUS LI-RADS) for the diagnosis of hepatocellular carcinoma: a pictorial essay. Ultraschall Med 2017;38:320-324

67. Aubé C, Oberti F, Lonjon J, Pageaux G, Seror 0, N'Kontchou G, et al. EASL and AASLD recommendations for the diagnosis of HCC to the test of daily practice. Liver Int 2017;37:1515-1525

68. American College of Radiology. Ultrasound LI-RADS ${ }^{\circledR}$ v2017. American College of Radiology Web site. https://www.acr. org/clinical-resources/reporting-and-data-systems/li-rads/ ultrasound-li-rads-v2017. Accessed January 1, 2019

69. Joo I, Lee JM, Lee DH, Jeon JH, Han JK. Retrospective validation of a new diagnostic criterion for hepatocellular carcinoma on gadoxetic acid-enhanced MRI: can hypointensity on the hepatobiliary phase be used as an alternative to washout with the aid of ancillary features? Eur Radiol 2019;29:1724-1732

70. Farinati F, Sergio A, Baldan A, Giacomin A, Di Nolfo MA, Del Poggio $P$, et al. Early and very early hepatocellular carcinoma: when and how much do staging and choice of treatment really matter? A multi-center study. BMC Cancer 2009;9:33

71. Kim YY, An C, Kim S, Kim MJ. Diagnostic accuracy of prospective application of the liver imaging reporting and data system (LI-RADS) in gadoxetate-enhanced MRI. Eur Radiol 2018;28:2038-2046

72. Joo I, Lee JM, Lee DH, Ahn SJ, Lee ES, Han JK. Liver imaging reporting and data system v2014 categorization of hepatocellular carcinoma on gadoxetic acid-enhanced MRI: comparison with multiphasic multidetector computed tomography. J Magn Reson Imaging 2017;45:731-740

73. Choi SH, Lee SS, Kim SY, Park SH, Park SH, Kim KM, et al. Intrahepatic cholangiocarcinoma in patients with cirrhosis: differentiation from hepatocellular carcinoma by using gadoxetic acid-enhanced MR imaging and dynamic CT. Radiology 2017;282:771-781

74. Bolondi L. Screening for hepatocellular carcinoma in cirrhosis. J Hepatol 2003;39:1076-1084

75. Singal A, Volk ML, Waljee A, Salgia R, Higgins P, Rogers MA, et al. Meta-analysis: surveillance with ultrasound for earlystage hepatocellular carcinoma in patients with cirrhosis. Aliment Pharmacol Ther 2009;30:37-47

76. Besa C, Lewis S, Pandharipande PV, Chhatwal J, Kamath A, Cooper N, et al. Hepatocellular carcinoma detection: diagnostic performance of a simulated abbreviated MRI protocol combining diffusion-weighted and T1-weighted imaging at the delayed phase post gadoxetic acid. Abdom Radiol (NY) 2017;42:179-190

77. Marks RM, Ryan A, Heba ER, Tang A, Wolfson TJ, Gamst AC, et al. Diagnostic per-patient accuracy of an abbreviated hepatobiliary phase gadoxetic acid-enhanced MRI for hepatocellular carcinoma surveillance. AJR Am J Roentgenol 2015;204:527-535

78. Tanaka H, Iijima H, Nouso K, Aoki N, Iwai T, Takashima T, et al. Cost-effectiveness analysis on the surveillance for hepatocellular carcinoma in liver cirrhosis patients using contrast-enhanced ultrasonography. Hepatol Res 2012;42:376384

79. Jang KM, Kim SH, Kim YK, Choi D. Imaging features of subcentimeter hypointense nodules on gadoxetic acidenhanced hepatobiliary phase MR imaging that progress to hypervascular hepatocellular carcinoma in patients with chronic liver disease. Acta Radiol 2015;56:526-535

80. Wang JH, Changchien CS, Hu TH, Lee CM, Kee KM, Lin CY, et al. The efficacy of treatment schedules according to Barcelona clinic liver cancer staging for hepatocellular carcinoma survival analysis of 3892 patients. Eur J Cancer 2008;44:10001006

81. Hatanaka K, Kudo M, Minami Y, Maekawa K. Sonazoidenhanced ultrasonography for diagnosis of hepatic malignancies: comparison with contrast-enhanced CT. Oncology 2008;75 Suppl 1:42-47 